Universidad de Lima

Facultad de Comunicación

Carrera de Comunicación

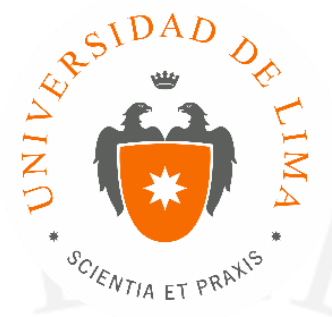

\title{
DESARROLLO DEL MICROPROGRAMA FIGURA Y SALUD
}

Trabajo de Suficiencia Profesional para optar el Título Profesional de Licenciado en Comunicación

\section{Jimmy Daniel Johnson Ricaurte \\ Código 20062585}

Asesor

Julio Wissar Rodríguez

$$
\text { Lima - Perú }
$$

Noviembre de 2017 


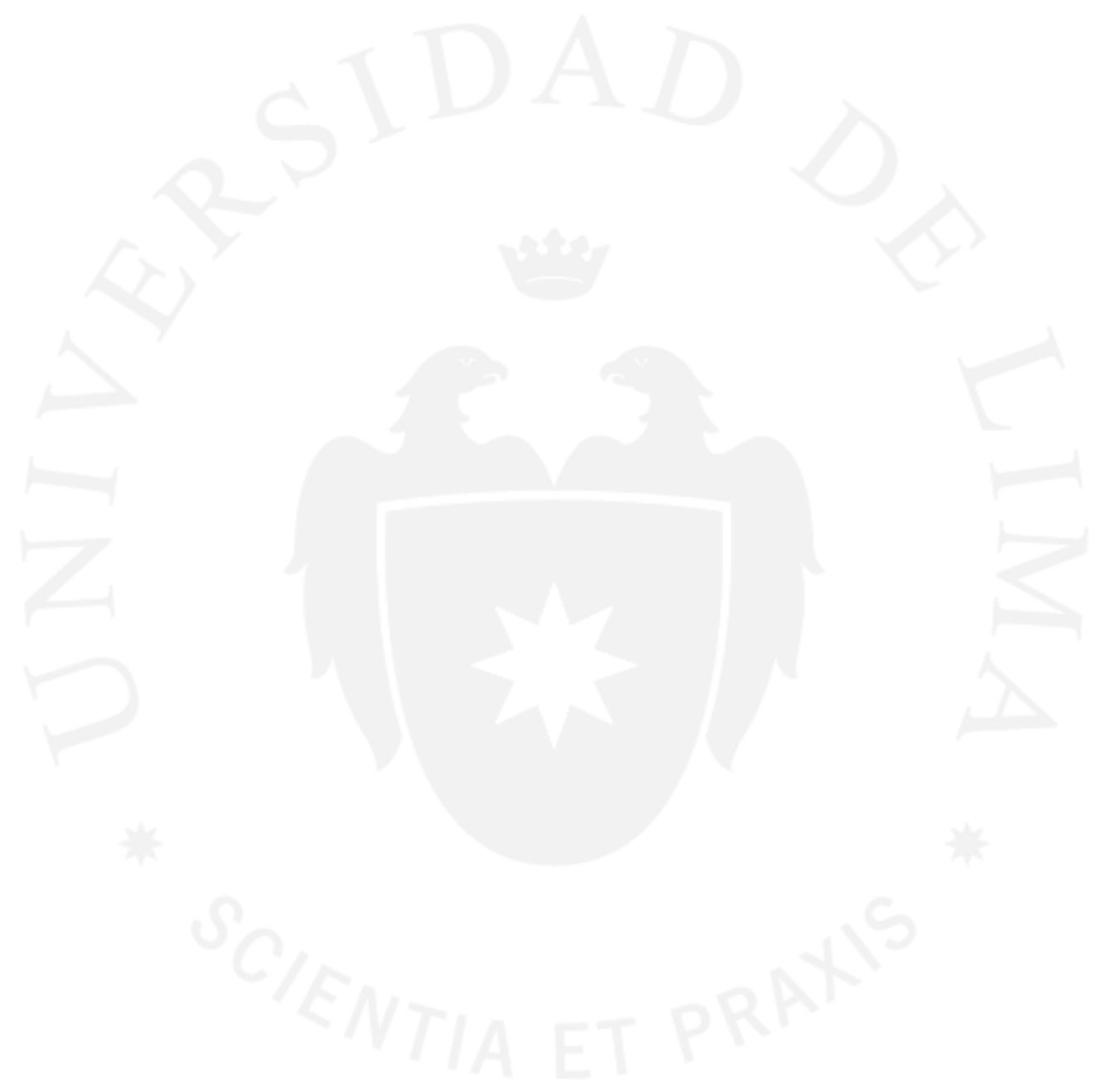




\section{DESARROLLO DEL MICROPROGRAMA}

FIGURA Y SALUD 


\section{ÍNDICE}

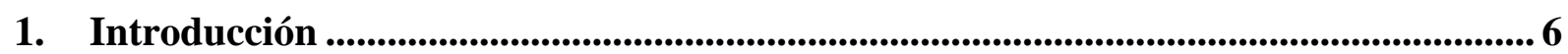

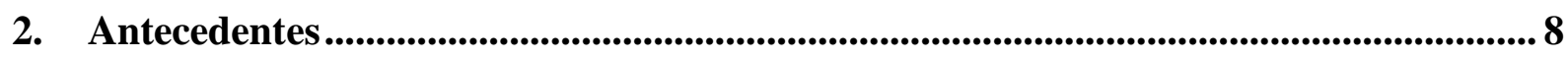

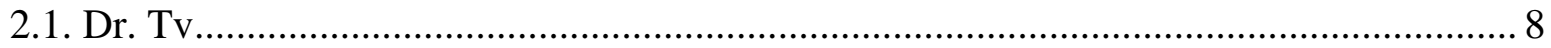

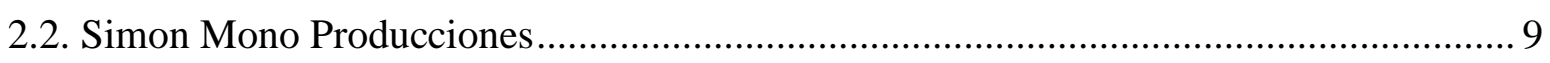

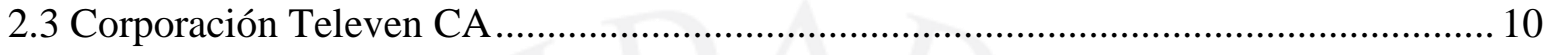

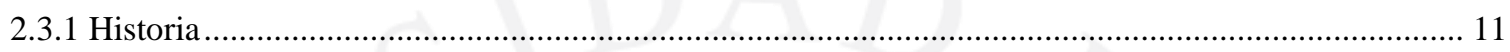

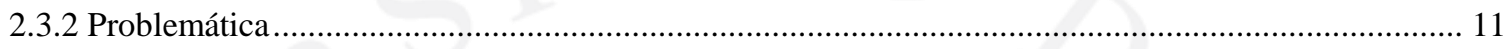

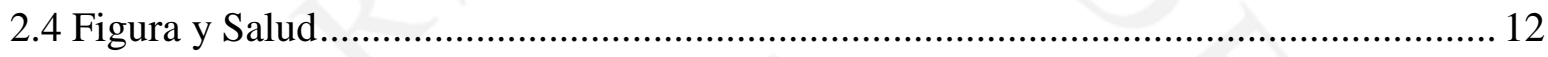

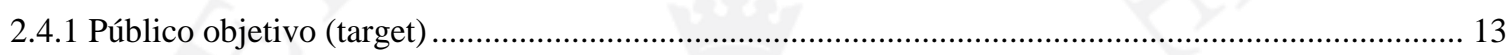

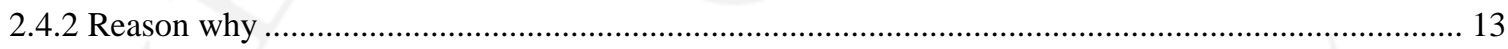

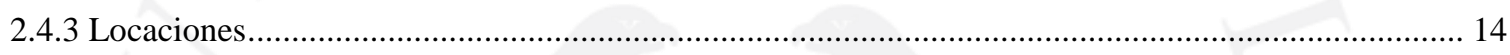

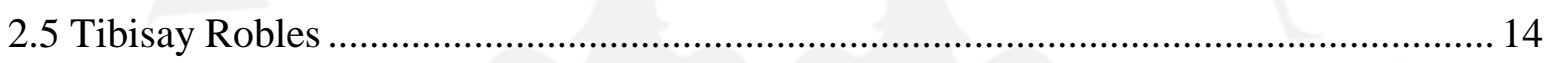

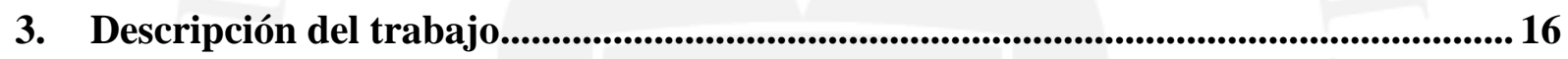

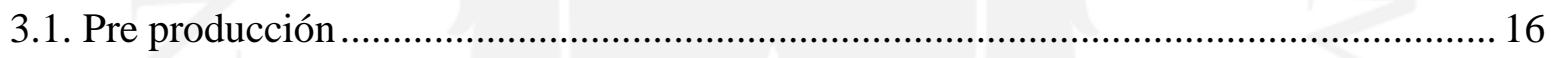

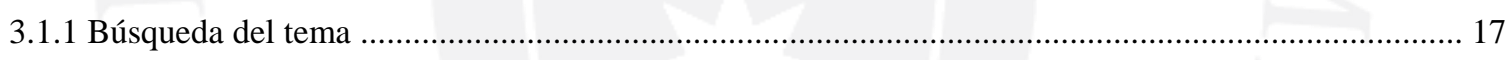

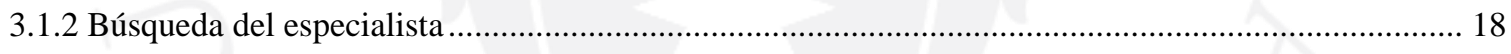

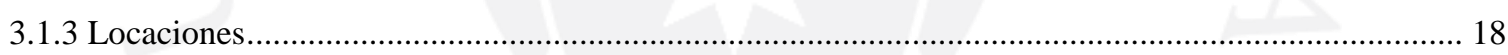

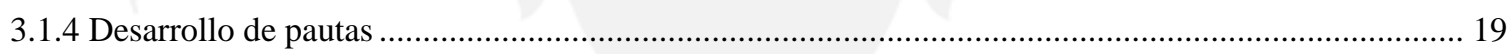

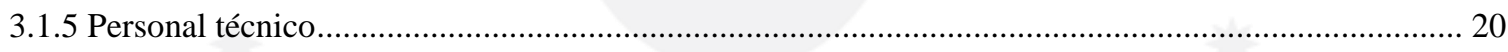

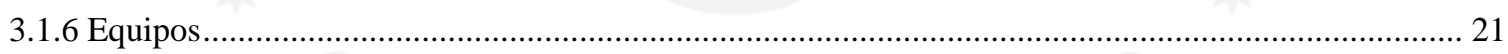

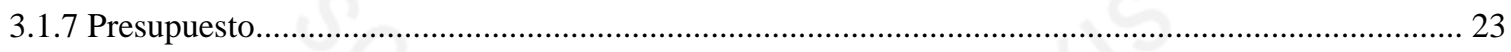

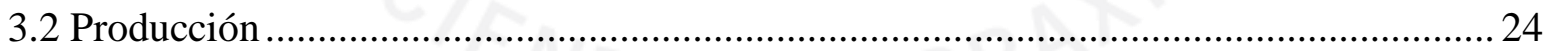

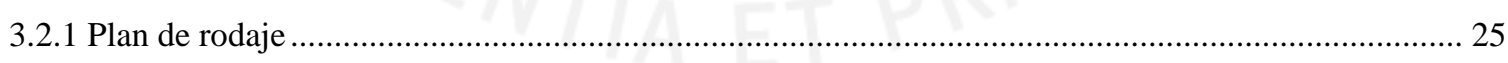

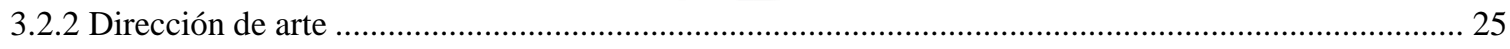

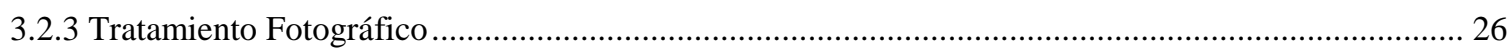

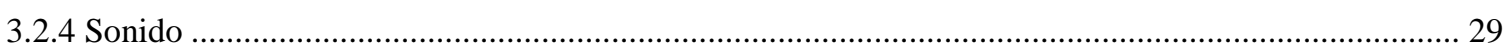

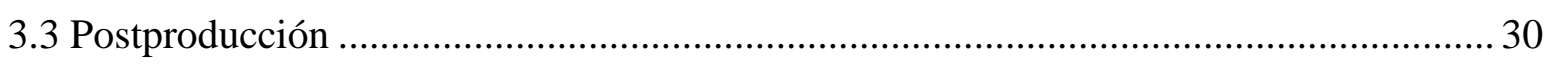

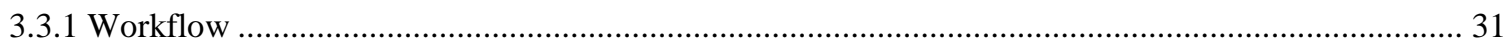

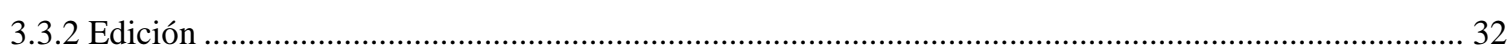

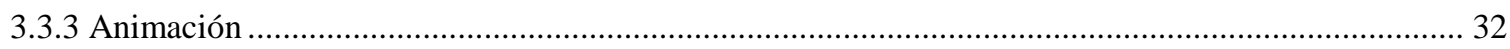

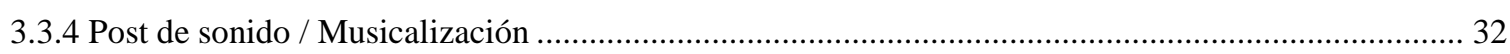

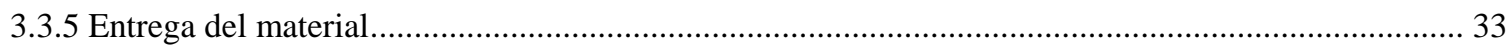




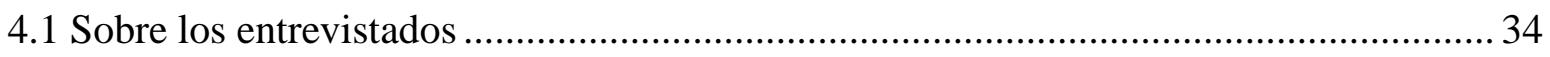

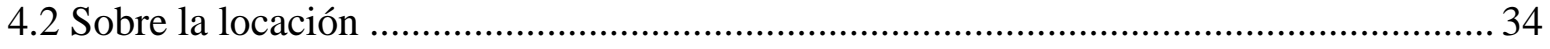

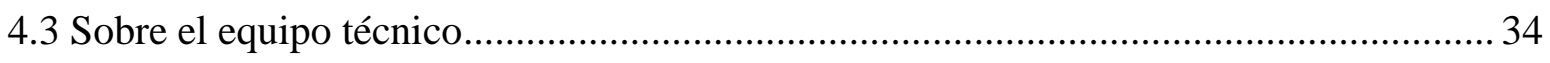

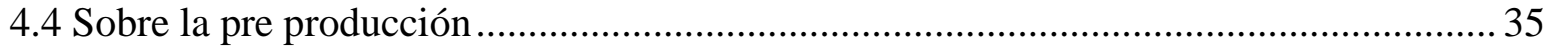

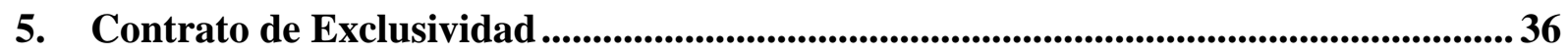

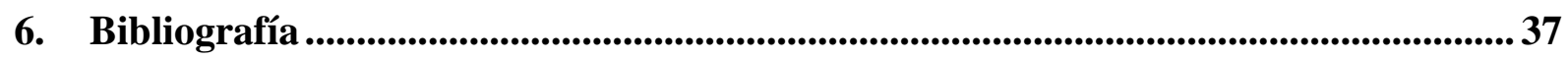




\section{Introducción}

El presente proyecto describe todo el proceso de producción del programa Figura y Salud, que se transmite en Venezuela de lunes a viernes en televisión abierta, dentro del magazine matinal Vitrina.

Como bachiller en comunicación audiovisual y gerente propietario de la empresa Simon Mono producciones, tuve la oportunidad de encargarme de todo el proceso que implica la realización de un programa como éste en su faceta internacional.

Dicha realización implicó un gran reto como profesional, ya que la temporada grabada en Perú fue desarrollada netamente por mí en cuanto a producción. Hubo varios factores considerados para que una sola persona se encargue de este proceso, manteniendo la calidad exigida por la casa realizadora matriz en Venezuela. Uno de los factores principales fue la búsqueda de condiciones óptimas que faciliten la realización en cuanto a locaciones y requerimientos técnicos. Éste y otros puntos serán tratados a detalle más adelante.

Al asumir el desarrollo y la realización de este programa asumí también una gran responsabilidad, teniendo a cargo una producción internacional con altos estándares de calidad. Ponderé el peso de cada una de las áreas esenciales para la realización, tomando como principales la dirección del entrevistado, el sonido y la dirección de planos. Mi intención fue que el reto de cumplir con las exigencias de la productora matriz trabajando solono repercutiera en el resultado final. Por ello, el trabajo fue exhaustivo durante la preproducción, respecto a la búsqueda y coordinación con los especialistas, quienes facilitaron el trabajo de grabación con una gran predisposición y ayuda para ingresar a sus consultorios y concluir con éxito.

Existen varios factores personales que influyen mucho en el desarrollo de este tipo de producciones, en las que la realización recae en una sola persona, entre ellos el orden y organización. Una correcta planificación y la disciplina desde la preproducción hasta la propuesta en post producción, se convirtieron en cualidades indispensables que lograron crear sinergia y facilitaron el trabajo en cada una de las locaciones donde se realizaron las grabaciones. Puedo destacar la colaboración de cada uno de los especialistas y el personal técnico, que fue el necesario para llevar a cabo este trabajo. 
En las siguientes páginas explicaré cada uno de los procesos que tuve que enfrentar, desde la preproducción, selección de especialistas, selección del tema, estudio de locaciones, desarrollo de planos, tiempo de postproducción y finalmente la entrega al equipo de producción venezolano para que concluya los puntos finales.

Con este proyecto profesional quiero demostrar que sí es posible desarrollar una producción o micro producción con una sola persona, siempre y cuando se tengan en cuenta factores claves o puntuales que ayuden a mantener una organización y orden. De esta manera, se puede cumplir con los objetivos trazados, proporcionando un servicio final de calidad. 


\section{Antecedentes}

\subsection{Dr. Tv}

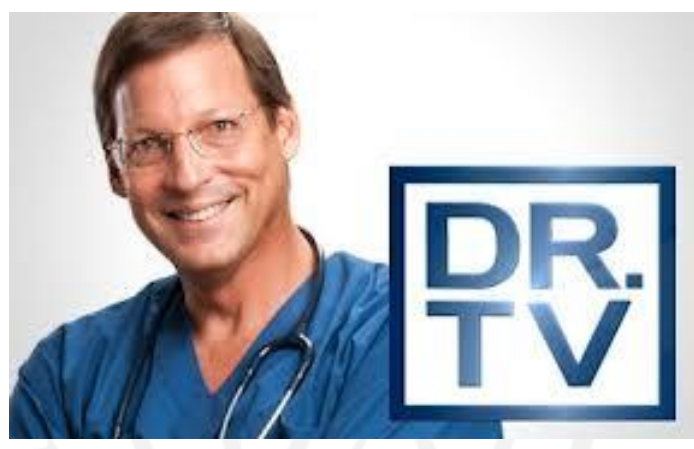

Es un talk show médico peruano producido por GV producciones, basado en el programa estadounidense The doctor Oz show. Tuvo su primera emisión el 26 de marzo 2012 por el canal 4 de América Televisión bajo el mando de Dr. Tomás Borda, quien interactúa con el público presente, exponiendo temas de interés colectivo. El programa tiene como objetivo brindar posibles soluciones y recomendaciones de enfermedades que acogen a la mayoría de la población.

El programa cuenta con invitados especialistas en diferentes áreas de medicina, quienes mediante ejemplos interactivos ayudan a comprender la complejidad y riesgo futuro de una enfermedad en el caso de que no sea tratada a tiempo.

Si bien es cierto este programa tiene ciertas diferencias con Figura y Salud, tanto por el formato como por el contenido, vale mencionar que también mantiene ciertas similitudes, como por ejemplo, el hecho de tratar temas médicos de actualidad relevantes, la invitación de especialistas para que profundicen en el tema y el motivar a la población a que se realicen chequeos cada cierto tiempo con el fin de prevenir enfermedades, etc.

Considerando que $D r . T v$ es un programa televisivo completo como tal, con mayor duración de tiempo y pautas comerciales, Figura y Salud, con sus tres minutos al aire, aborda más temas que suelen ser importantes para el público general, como son el deporte, medicina estética, salud mental, etc.

Una ventaja moderna es que, por la duración que tiene Figura y Salud, puede ser compartido en redes sociales con fácil distribución y aceptación, lo que vuelve al microprograma una fuente de referencia importante sobre salud y belleza. 
Otro punto a favor que tiene Figura y Salud respecto a su referente peruano, es que al ser una producción multinacional, es decir, al interactuar con especialistas de diferentes partes del mundo, se encuentra un paso más adelante, ya que presenta las últimas tendencias en las áreas de salud, belleza y deporte.

\subsection{Simon Mono Producciones}

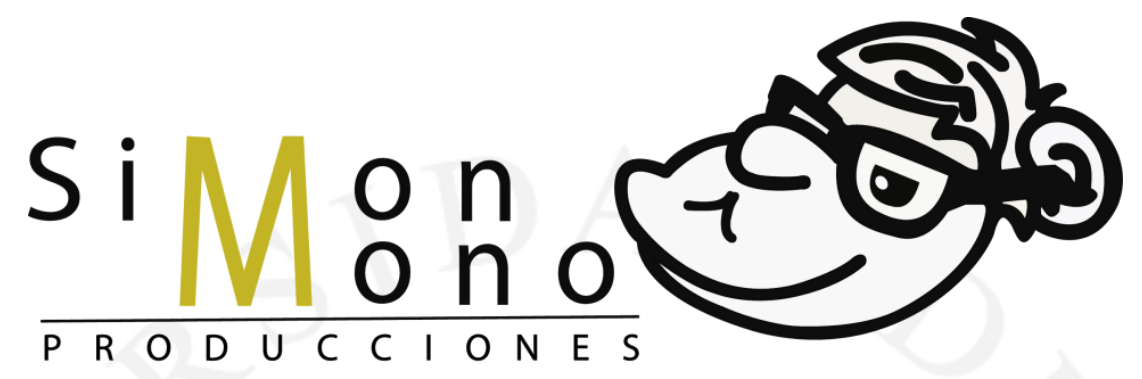

Simon Mono es una productora que inicia sus actividades en abril del 2012. Inicialmente se mantuvo realizando trabajos muy esporádicos, hasta que en el año 2014 se lograron realizar inversiones en equipos técnicos, con el objetivo de poder competir en el mercado audiovisual. En ese momento las producciones se realizaban en base a temas deportivos, principalmente a las artes marciales mixtas y deportes de contacto en general.

En el 2015 se decide expandir realizando videos institucionales y corporativos, logrando trabajar con clientes como KIA, Hyundai, PFC, Hersil, Sigma, entre otros. A finales de ese año, la productora venezolana Figura y Salud SA, se contacta con nosotros por recomendaciones y es así que Simon Mono comienza a trabajar con ellos y después de unas semanas de grabación, la productora decide entregarnos la representación para la realización en Perú, acuerdo que se mantiene hasta la actualidad.

Si bien es cierto que Simon Mono no tiene la producción total del programa Figura y Salud, puesto que depende de la matriz en Venezuela, sí tiene potestad para plantear los temas a tratar y escoger las locaciones donde se puedan efectuar las grabaciones, en países como Estados Unidos y Perú. Actualmente, Simon Mono Producciones es la empresa encargada de realizar la pre producción, producción y post producción.

Durante la pre producción su labor incluye:

- Búsqueda de información.

- Búsqueda del especialista. 
- Coordinación del equipo técnico.

- Coordinación catering.

- Coordinación de transporte.

- Armado del plan de rodaje.

- Desarrollo del guion.

Respecto a la producción, su trabajo consiste en:

- Alquiler de equipo técnico.

- Desarrollo de guion técnico.

- Desglose de producción.

En la etapa de post producción el trabajo es un poco diferente, ya que influye mucho lo que dictamine la productora en Venezuela. La labor depende de los requerimientos que tengan en post producción, mismos que pueden ir desde la sincronización del audio con el video, hasta el armado del programa, cuidando siempre los lineamientos que la casa realizadora exija.

\subsection{Corporación Televen CA}

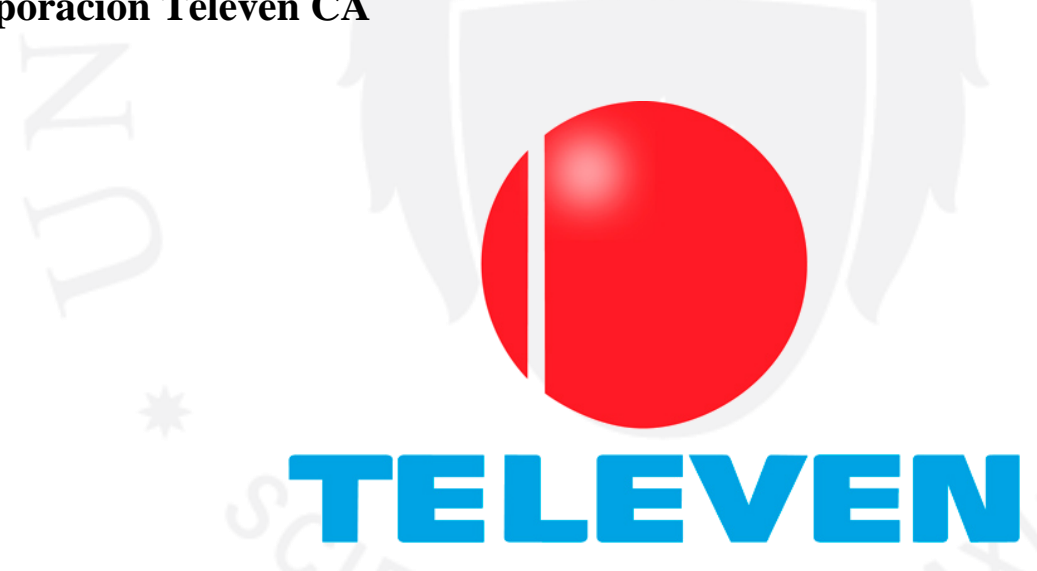

Corporación Televen es uno de los principales canales de televisión en Venezuela. Más conocido como Televen, es uno de los pocos canales que se mantienen en el sector privado, produciendo ellos mismos la mayoría de su contenido. Es tal el éxito y reconocimiento que tiene este medio de comunicación, que la mayoría de sus programas suelen ser tendencia en las redes sociales. 


\subsubsection{Historia}

En febrero de 1988 salió por primera vez la señal de prueba de Televen, que fue emitida por el canal 10 en Caracas, cubriendo por el momento solo el área metropolitana. En sus inicios Televen no contaba con producción propia, hasta que pocos meses después surgieron los primeros programas producidos por ellos mismos: Teledeportes con Max Lefeld, $\mathrm{VH}-10 \mathrm{con}$ Musiuito Lacavalerie y Fortuna 10 con Corina Azopardo.

Posteriormente, en marzo del 1989, el vicepresidente de producción de Televen anunció la adquisición de los teatros Cedros y Macaracuay, para convertirlos en estudios de televisión. Años después, durante la década de los 90, con la ayuda de inversores y personalidades de la televisión venezolana, Televen expandió rápidamente su cobertura a todo el país, logrando atraer a una audiencia más grande que la red estatal llamada Venezolana de Televisión. Por último Televen fue el primer canal de Venezuela en transmitir durante las 24 horas del día, primero los fines de semana y posteriormente todos los días.

\subsubsection{Problemática}

Para el 2015, la programación de Televen no contaba con un segmento o espacio dedicado al área de salud y belleza, donde se brindaran los nuevos avances, descubrimientos y tratamientos de las diferentes disciplinas para el cuidado de las personas. Por falta de segmentos como éste es que la casa realizadora comenzó a posicionar este proyecto, ya que debido a la situación en la que se encuentra Venezuela, la gente comenzó a buscar medios con los que pudiera satisfacer ciertas necesidades tanto de salud como de belleza. Es ahí donde Televen decide que Figura y Salud tenga un espacio todos los martes dentro del programa llamado Vitrina. 


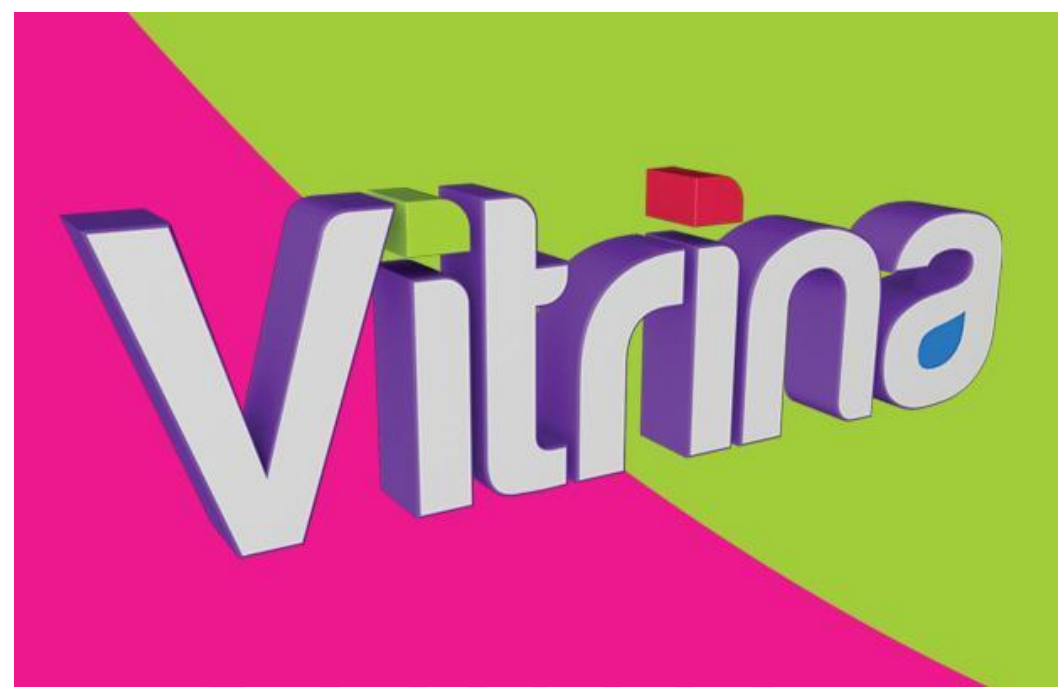

Vitrina es un magazine venezolano que se encuentra en el aire desde el 2011. Aborda temas tales como gastronomía, tips para el hogar, estilos de vida, etc. Éste programa tiene una frecuencia de emisión diaria (Lunes a Viernes) en horario matutino de 10 am a 11 am (incluidas las pautas comerciales).

Adherir Figura y Salud al programa Vitrina brindó la oportunidad de diferenciarse y asumir el liderazgo frente a otros canales de señal abierta. Según su productor Nelson Labrador, no contaban con programas que aborden temas como los mencionados anteriormente en televisión nacional (salud, belleza y deporte). Por ello lograron brindarle al público un espacio de información, interacción y conexión que va de la mano con la necesidad y realidad del país. Por otro lado, también se logró explotar la oportunidad de darle cierta ventana a especialistas, para que éstos pudieran comunicar sus conocimientos, nuevas técnicas y a la vez posicionarse en medios masivos, los cuales son de poco acceso debido a los elevados costos que representan.

\subsection{Figura y Salud}

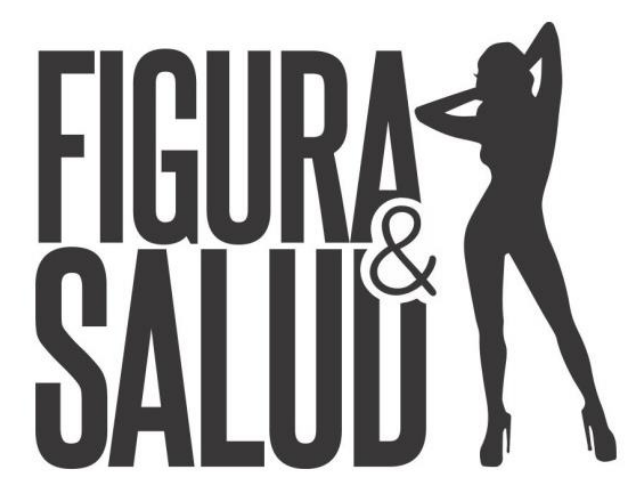


Es un programa de televisión de 3 minutos de duración, de frecuencia semanal, que mantiene un formato de micro programa o cápsulas de información, de última tendencia en el área de salud, nutrición, belleza, moda y acondicionamiento físico. Tiene por objetivo generar una mejor calidad de vida de sus espectadores.

Tal como lo mencionamos anteriormente, cada programa es grabado en escenarios nacionales e internacionales, manteniendo siempre espacios tanto urbanos como naturales "que le permitan al espectador tener elementos visuales característicos de un mundo globalizado y conectado", según su presentadora Tibisay Robles.

\subsubsection{Público objetivo (target)}

De acuerdo a un folleto de presentación promocional proporcionado por Tisibay Robles (productora general del programa), el público objetivo de Figura y Salud es el siguiente:

"Hombres y Mujeres de 24 a 60 años, seguidores de información en redes sociales y telespectadores de TV que buscan asesoramiento en áreas como nutrición, salud y belleza - en formato de cápsulas de información - para lograr un alto estándar en su calidad de vida ... como respuesta a las necesidades actuales del día a día."

\subsubsection{Reason why}

A partir de la misma fuente, el reason why es definido en estos términos:

- Áreas de mayor crecimiento en el sector media \& TV, dada su gran capacidad de influenciar al espectador en su estilo de vida.

- Visión innovadora en la integración de los temas al comportamiento del espectador, que incrementa sus indicadores de participación, frecuencia y posicionamiento.

- La credibilidad del host de Tibisay Robles, quien posee una trayectoria exitosa en la actuación, modelaje y sus logros internacionales como atleta de alto nivel en fisicoculturismo (categoría bikini). Además de su formación como asesora en el área de nutrición y acondicionamiento físico, que complementa con su rol de empresaria del sector salud.

- Creación de necesidad y generación de soluciones. Su formato all-in-one concentra áreas actuales de interés (salud, belleza y moda), por lo que el programa Figura y Salud genera motivación y seguimiento inmediato de la audiencia posicionando su slogan 
"Vivan una vida sana y activa... Amen su tiempo".

\subsubsection{Locaciones}

Dentro de las locaciones, entendidas como las ciudades y lugares más comunes dentro de cada de una de ellas, tenemos:

- USA: Miami, New York, Las Vegas.

- Perú: Lima (Boulevard Asia, Hotel Marriot, Larcomar, malecón de Miraflores).

- Aruba.

- Venezuela: Caracas (Hotel Renaissance By Marriot - Club Valle Arriba Athletic Center - Parque Nacional Galipan, Edo. Vargas: Spa Lomas de Caruao).

\subsection{Tibisay Robles}

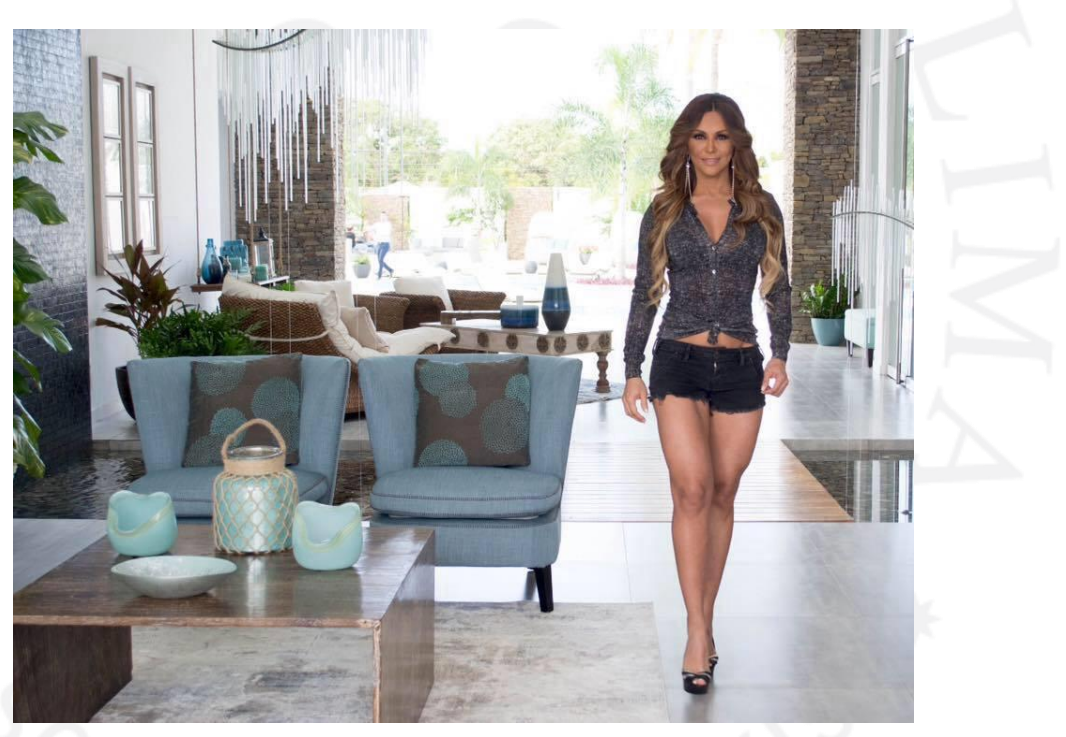

Nacida el 9 de junio de 1972 en la ciudad de San Pedro, Libertador, Distrito Capital, es una actriz venezolana, modelo, presentadora de televisión, productora ejecutiva, health coach y deportista de alto rendimiento, que inicia su vida en la televisión como actriz en el 2004 como coprotagonista interpretando a María Trinidad Guarache Mata en la famosa serie de comedia venezolana Guayoyo Express, la cual se mantuvo al aire por tres temporadas y tuvo records de rating ganándole incluso a la ya conocida serie colombiana Betty la Fea. 

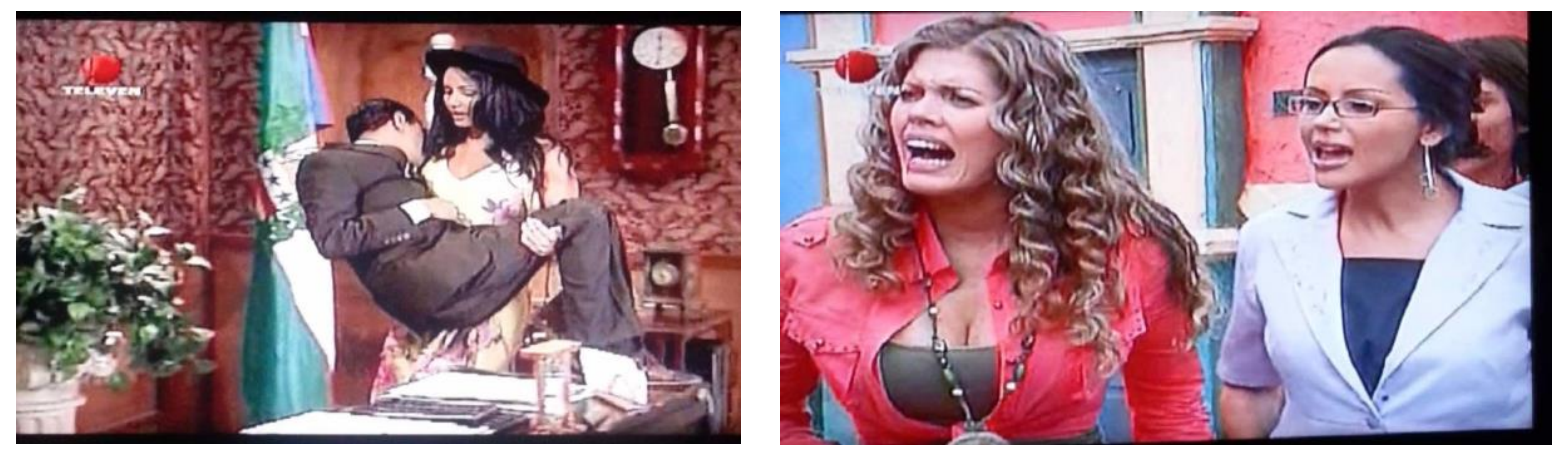

Este éxito le abrió paso a múltiples trabajos televisivos que la llevaron a ser muy conocida en Venezuela. Tiempo después decidió juntar sus dos pasiones que son la televisión y la salud. Es así como inicia Figura y Salud, que actualmente ya cursa por su cuarta temporada al aire junto con el programa de variedades Vitrina.

Tibisay Robles es también una conocida health coach, pues presta asesoría a nivel personal y corporativo promoviendo temas de nutrición e imagen. Actualmente está implementando un centro integral de Coaching4Life, en donde ofrecerá asesoría con su equipo de alto nivel profesional. 


\section{Descripción del trabajo}

\subsection{Pre producción}

La pre producción es la etapa en la cual se inicia todo el trabajo audiovisual y abarca todas la necesidades y coordinaciones previas al comienzo de la grabación. Esta primera etapa es importante para no sufrir mayores contratiempos durante la producción de cualquier trabajo audiovisual.

En una primera instancia se recibe el guion literario en manos del realizador, comenzando normalmente con el desglose del mismo. Así se tiene un primer acercamiento de cuántos días de grabación se necesitan, cuántas locaciones, personal y equipo técnico, días de edición, horarios de grabación, etc.

En el caso de Figura y Salud, cada uno de los guiones literarios son enviados por la matriz (Venezuela) con ciertas sugerencias de planos o locaciones que puedan ser utilizados en Perú. Dichas sugerencias igual dejan la libertad de que la casa realizadora local haga los ajustes necesarios para llegar a las referencias dadas por la productora venezolana.

En Figura y Salud al ser una producción multinacional, la pre producción está determinada por los requerimientos de cada programa, es decir que podría desarrollarse la entrevista al especialista en Perú, y las tomas de la presentadora en Estados Unidos. Es por eso que la fase de pre producción en este caso tiene muchísima importancia, ya que la coordinación no solo recae a un país o productora en especial, sino que es el conjunto del trabajo ejecutado por varias casas realizadoras en diferentes países.

Al momento en que la matriz de Figura y Salud SA envía el requerimiento, el área de pre producción de Simon Mono Producciones comienza con el desglose del mismo, el cual comprende la investigación de los temas relevantes y de actualidad, la búsqueda de los especialistas que sustenten o expliquen de manera amena cada uno de los temas a tratar, la coordinación con los especialistas, los permisos para el uso de sus instalaciones, o si no es posible grabar en ellos, la búsqueda de una locación acorde al tema central del programa. Luego se conversa y coordina con el personal técnico, definiendo el tipo de equipos audiovisuales que serán necesarios para el desarrollo del tema (cámara, iluminación, sonido, isla de edición, etc.)

Cabe recalcar que dentro de esta etapa se adapta la dialéctica de la presentadora a los 
especialistas (internacionales) y a un contexto del mercado venezolano. Si bien es cierto no se le cambia la forma o estilo que puede tener el especialista al momento de hablar, se cuida que no se utilicen palabras que puedan tener un significado o connotación diferente en Venezuela, ya que pueden alterar la susceptibilidad del público local.

\subsubsection{Búsqueda del tema}

Manteniendo la línea y los parámetros que exige la productora, la búsqueda de los temas para la presentación del programa es de suma importancia, puesto que éstos tienen que ser actuales y estar a la vanguardia tanto en medicina como en belleza o deporte. Otro punto importante a la hora de buscar los contenidos es que estos sean coyunturales con la realidad venezolana. Por ejemplo, si en este momento se encuentra en auge la enfermedad del Zika, es de vital importancia que el programa gire en torno a esta enfermedad. De esta manera se brinda información de actualidad que pueda orientar a la prevención y qué posibles tratamientos se pueden tomar para ayudar a mejorar la calidad de vida del público.

Este paso es el que va a brindar la columna vertebral del programa, ya que según el tema, se derivarán las diferentes áreas para el desarrollo del guion, además del cuestionario para el especialista donde se resolverán las principales dudas del público.

Otra fuente importante sobre la información que se brindará en los programas son las redes sociales. Los espectadores exponen casos relevantes que les gustaría sean tratados por la presentadora y los especialistas. De este modo la producción logra generar aún más interés dentro del público, atendiendo sus solicitudes.

En conclusión, la búsqueda del contenido para Figura y Salud se desarrolla en base a 3 aristas que son:

- Coyuntura social.

- Información relevante de actualidad.

- Propuesta del público. 


\subsubsection{Búsqueda del especialista}

Una vez obtenido el tema y de haber ahondado en el mismo, se buscan a los mejores exponentes o especialistas dentro del área a tratar. Es ahí donde el equipo de pre producción, mediante referencias, títulos, galardones, etc., realiza el contacto con los especialistas para lograr tener citas previas con ellos, en las que se aborden los temas a tratar. Además, en dichas visitas se evalúa la facilidad de palabra que cada especialista tiene frente a la cámara. Al mismo tiempo, al momento de tener la primera cita con cada especialista, se procede a verificar el lugar para determinar qué personal y equipos técnicos se van necesitar para el día de la grabación. Así mismo se procede a verificar las conexiones eléctricas para no causar ningún tipo de corte durante la grabación.

Por otro lado, se verifica el tipo de instrumentación con que cuenta el especialista dentro de su centro de labores, ya que muchos de los textos que van a ser explicados irán reforzados con imágenes de apoyo, por lo que es de vital importancia que el especialista pueda aplicar su técnica frente a las cámaras con el objetivo de brindar más dinamismo al programa.

\subsubsection{Locaciones}

Por lo general se manejan dos tipos de locaciones:

- Para la presentadora.

- Para los especialistas.

Para la presentadora, generalmente se suelen utilizar sitios turísticos representativos de la ciudad en donde se realice la grabación. Normalmente se utilizan espacios abiertos, donde predomine la naturaleza.
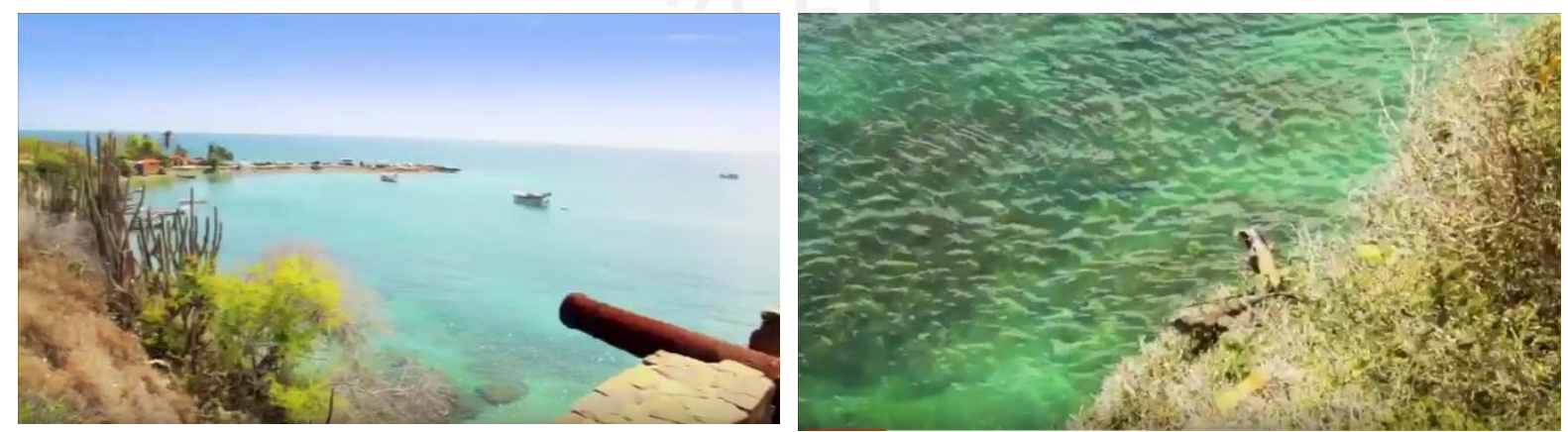


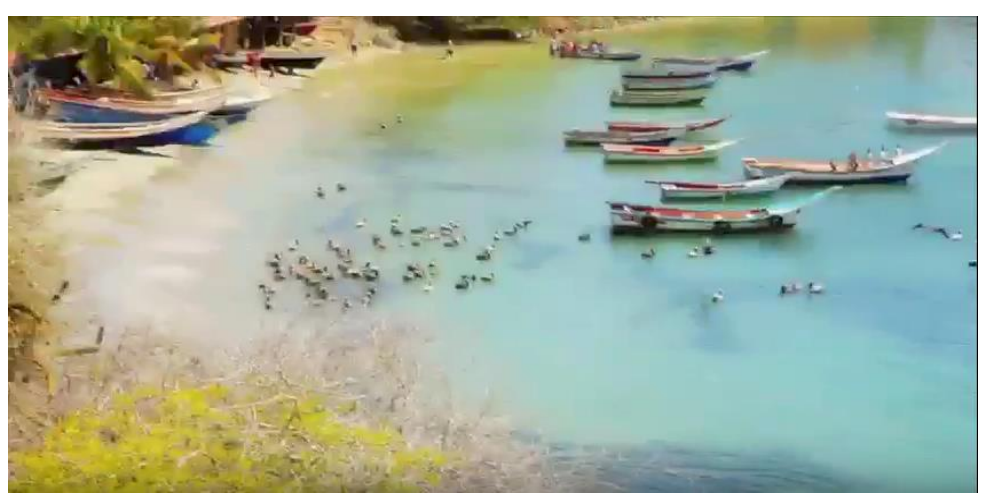

Este tipo de locaciones con espacios abiertos suelen ser parte del pedido general de la productora Figura y Salud SA, puesto que según sus parámetros, los planos a utilizarse en el momento de la presentación tienen que ser de general a tres cuartos, y para la introducción al tema un plano medio de la presentadora. Este mismo criterio se utiliza al momento de realizar el cierre del programa.

Para los especialistas, por lo general se suelen usar los mismos ambientes en donde éstos laboran, esto con el fin de que denoten confianza y muestren la experiencia que tienen. En este tipo de grabaciones no hay un manual que marque los parámetros a usar, puesto que cada consultorio, gabinete de belleza o gimnasio tienen diferentes estructuras y espacios. De este modo la producción y los planos se adaptan según el lugar y las acciones que vaya a realizar el especialista.

\subsubsection{Desarrollo de pautas}

Una vez realizada la investigación del tema, parte del equipo de pre producción comienza a preparar el opening para la introducción, que deberá decir la presentadora al momento de dar la bienvenida al programa. En estas pautas se cuida mucho de no brindar información relevante, ya que todas las especificaciones estarán a cargo del especialista.

Estas pautas son revisadas cuidadosamente por la presentadora y ensayadas en cámara con el objetivo de poder pulir y ajustar el texto.

Dentro de esta etapa también se marcan las menciones de los auspiciadores, que van de la mano de tomas de apoyo del lugar, y que tienen un tiempo específico para ser mencionadas, ya que al ser un programa de poca duración, distribuir bien el tiempo es clave para brindarle espacio suficiente al especialista, permitiendo que pueda resolver los principales interrogantes de los temas a tratar. 
Todas estas menciones publicitarias son acordadas y trabajadas por la producción al momento de buscar la locación. En esta se maneja el canje como medio de pago, aludiendo siempre a la exposición internacional que su marca va a tener gracias al programa Figura y Salud.

Dentro de las pautas establecidas en temporadas previas a la internacionalización del programa, por lo general todas las tomas de apoyo de lo que exponían los especialistas eran básicamente fotos compradas por la productora, con lo que al momento de llegar a Perú se les ofreció optar por grabar las tomas de apoyo in situ y de la mano del mismo especialista. Sin embargo, no todos los temas pueden ser reforzados con tomas de apoyo en video, por lo que a veces suele volver a utilizarse el recurso de las fotos, ya que recrear algunos tipos de escenas excede del tiempo establecido por la productora. Es por eso que, según el tema, se incluye en la pauta el tiempo necesario para grabar las imágenes de apoyo en video, con el fin de afianzar más al público con la práctica en vivo de los especialistas.

\subsubsection{Personal técnico}

Dentro de los cargos habituales que se manejan en una producción como ésta, en este caso, la dirección, fotografía, sonido, producción, script y edición fueron realizados por Jimmy Johnson, director de la empresa Simon Mono Producciones, ya que por compromisos previamente asumidos por la empresa el personal no pudo asistir a la grabación de los especialistas en Perú, por lo que él tuvo que asumir todos los cargos para el correcto desarrollo de la producción.

Para el correcto funcionamiento de cada una de las áreas, el director tuvo que previamente elegir las locaciones, armar plan de rodaje, realizar un shooting y demás coordinaciones que agilicen y faciliten la grabación de cada uno de los programas, con el objetivo de cumplir con los tiempos brindados por la productora ejecutiva Tibisay Robles.

En este caso en particular, la búsqueda de los especialistas y la coordinación previa fue desarrollada desde la matriz en Venezuela, enviando a Simon Mono Producciones los detalles para que las entrevistas sean concretadas y coordinadas. La mayoría de los programas a grabar para esa temporada iban a realizarse en diferentes países, y a Perú se le destinó únicamente la grabación de los especialistas tanto en las áreas de medicina deportiva y estética, así como las de belleza y acondicionamiento físico. 
Frente al desafío de tener que ocuparse de todos los cargos y estar al tanto de muchos aspectos, fue de vital importancia para el director haber estudiado minuciosamente el tema y tener todo correctamente coordinado, para no olvidar ningún detalle al momento de realizar la edición. A esto hay que sumarle el hecho de que se tuvo que poner mucha atención al encuadre, iluminación y sonido, para que estén correctamente delimitados y así no perder calidad en la grabación. Cabe resaltar que se necesitó muchísima colaboración por parte de cada uno de los especialistas, ya que sin su buena predisposición, la dirección general de todos los cargos técnicos más la guía de las entrevistas hubiese sido casi imposible.

Una vez terminada la grabación, se pasó al área de post producción, en donde, por orden de la matriz, en un primer momento solo se necesitó la sincronización del audio con el video, para que la productora ejecutiva pueda revisar el material grabado. Posteriormente se inició una edición a manera de corte grueso, en la que se ordenaron cada de una de las respuestas emitidas por el especialista. Así mismo se trabajó la información para que coincida con el tiempo determinado por la productora.

En el caso de los programas que fueron completamente grabados en Perú, Simon Mono Producciones se encargó de realizar la edición íntegra del mismo, que va desde la sincronización del audio hasta el envío final a Venezuela, donde posteriormente es transmitido en el programa Vitrinia los días martes. Por lo general, la productora ejecutiva, Tibisay Robles, viajó al Perú para estar al tanto del rodaje y post producción de la temporada hasta el término de la misma.

\subsubsection{Equipos}

Según los estándares de la casa televisora Televen, existen aspectos técnicos indispensables de calidad que no pueden ser vulnerados. Dentro de los aspectos técnicos se pide:

\section{Cámara}

- 1920 x 1080 (Full HD)

- Set de lentes

\section{Audio}

- Boom

- Micrófonos lavalier o de solapa 


\section{Iluminación}

- Pack de luces (1000 leds)

- Maleta de 3 fresneles de 650w

\section{Accesorios}

- Trípode

- Slider

- Mini jib

- Claqueta
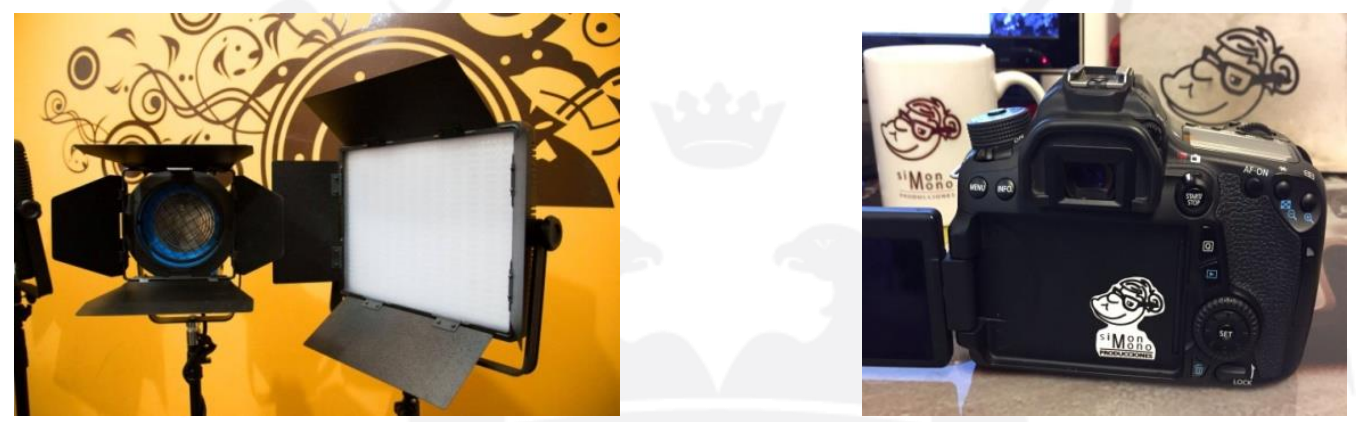

Para mantener la calidad exigida se optó por usar una cámara Canon modelo 70D con un set de lentes macro, $50 \mathrm{~mm}$ fijo y $22-70 \mathrm{~mm}$.

Para la fotografía no hay una exigencia determinada, lo que piden que es el tipo de luz que se utilice tiene que simular la luz natural que tienen los consultorios o espacios a grabar. Además exigen que sea una luz sobria y de relleno, que mantenga ambiente natural de la locación. Es por eso que se optó por un set de luces led que tenga variabilidad de temperaturas de 3200k a 5500k, con un panel de 1000 leds, suficientes para rellenar el espacio. A esto se le sumaron 3 luces de 800 leds cada una con la misma variabilidad de temperatura, que fueron usadas sobre todo para iluminar fondos y brindar backs a los entrevistados y para ciertos planos detalle.

En lo que corresponde al audio, se utilizaron micrófonos lavalier profesionales Senheiser, conectados a una grabadora de audio, donde se pudieran ajustar los niveles según el entrevistador, así como monitorear que el audio fuera grabado lo suficientemente limpio como para que se trabaje sin problemas en post producción. 
Para estas grabaciones se utilizaron diversos elementos que facilitaron el rodaje, tales como trípode, glide cam, slider, etc. Cada una de estas herramientas fue utilizada en partes específicas. Por ejemplo:

- Todas las tomas de entrevistas a los especialistas fueron realizadas con trípode, por requerimiento de la matriz.

- Para las tomas de apoyo se utilizaron tanto el glide cam como el slider, con la finalidad de que se consiguiera la mayor estabilidad posible, previniendo cualquier tipo de movimiento de cámara no deseado que generase distracción, lo que haría perder la concentración al espectador.

\subsubsection{Presupuesto}

Dentro del presupuesto se incluyeron todos los equipos técnicos necesarios para realizar de manera óptima la grabación. Para determinar estos costos siempre es necesario un previo análisis de lo que se va a llevar a cabo, y es de extrema importancia la planificación, ya que por ejemplo, si dentro de la grabación hay que contemplar un viaje, hospedaje y viáticos, éstos gastos deben ser considerados. En general, para la realización en una locación determinada, la casa realizadora debe considerar el costo que implica llegar a ellos, para no incurrir con valores en contra a los establecidos y ya pautados con anticipación por ambas partes.

Además, al plantear un presupuesto es importante considerar qué situaciones y elementos serán parte de una reducción de costos, sin dejar de cumplir con los tiempos previamente planteados.

Tomando en cuenta que parte de la realización de esta temporada estuvo a cargo de una sola persona, una buena pre producción fue clave para el desarrollo exitoso de Figura y Salud Perú. Para esto se implementó un nuevo esquema de valor propuesto por la productora Simon Mono Producciones, a cargo de Jimmy Johnson, en el cual se planteó convertir al especialista en un aliado estratégico, dejando de lado el enfoque tradicional de costo. Con ello se logró obtener un ahorro en el presupuesto de las locaciones frente a otras temporadas realizadas en otros países. 


\section{Ejemplo de presupuesto}

\section{PRESUPUESTO}

Presupuesto: PROGRAMA FIGURA Y SALUD

Solicitante: TIBISAY ROBLES

Fechas: POR DEFINIR

Empresa: FIGURA Y SALUD SAC

\begin{tabular}{|c|c|c|c|c|}
\hline Necesidades & Cantidad & Fechas & $\begin{array}{c}\text { Planeado } \\
\text { V.Unit. } \\
\text { S/. }\end{array}$ & $\begin{array}{c}\text { Planeado } \\
\text { Total } \\
\text { S/. }\end{array}$ \\
\hline \multicolumn{5}{|l|}{ Personal tecnico } \\
\hline Director & 1 & 2 & $S / .1 .000,00$ & $S / .2 .000,00$ \\
\hline Productor & 1 & 2 & $\mathrm{~S} / .500,00$ & $S / .1 .000,00$ \\
\hline Camarografo & 1 & 2 & $S / .500,00$ & $S / .1 .000,00$ \\
\hline \multicolumn{5}{|l|}{ Equipo } \\
\hline Camara DSLR con set Lentes & 1 & 2 & $S / .200,00$ & $S / .400,00$ \\
\hline Glide Cam & 1 & 2 & $S / .100,00$ & $S / .200,00$ \\
\hline MiniJib & 1 & 2 & $S / .100,00$ & $S / .200,00$ \\
\hline Tripode & 1 & 2 & $S / .50,00$ & $S / .100,00$ \\
\hline Set Luces & 1 & 2 & $S / .300,00$ & $S / .600,00$ \\
\hline Micrófonos tipo pechero y Boom & 1 & 2 & $S / .100,00$ & $S / .200,00$ \\
\hline slider & 1 & 2 & $S / .100,00$ & $S / .200,00$ \\
\hline \multicolumn{5}{|l|}{ Servicios } \\
\hline Movilidad & 1 & 2 & $S / .200,00$ & $S / .400,00$ \\
\hline Imprevistos & 1 & 1 & $S / .300,00$ & $S / .300,00$ \\
\hline \multicolumn{5}{|l|}{ Post Produccion } \\
\hline Isla edición & 1 & 3 & $S / .100,00$ & $S / .300,00$ \\
\hline Animador & 1 & 1 & $S / .300,00$ & $S / .300,00$ \\
\hline editor & 1 & 3 & $S / .200,00$ & $S / .600,00$ \\
\hline
\end{tabular}

Nota: Los precios no incluyen IGV.

Precios expresados en nuevos soles.

Forma de pago: $\mathbf{5 0 \%}$ a la aceptación del presupuesto.

Saldo al finalizar el evento.

Validación del presupuesto: 10 días

\subsection{Producción}

Debido a que en esta oportunidad una sola persona era la encargada de todo los cargos, la parte de producción fue tomada muy en cuenta para que en el momento de iniciar el rodaje de la temporada no haga falta nada que sea de suma importancia y que impida el normal desarrollo de la grabación. Para esto se tomaron varias precauciones como lista de equipos técnicos, preguntas a los especialistas, permisos y coordinaciones, armado de horarios, movilidad, lista de direcciones de los locales. etc. 


\subsubsection{Plan de rodaje}

Luis Alfredo Landavere, en su libro Supervivencia audiovisual, comenta que el plan de rodaje es un cronograma estratégico que se realiza en base a la producción, locación, ubicación de las locaciones, cantidad de planos, distancia entre locaciones, etc. Éste se arma de manera estratégica con el fin de marcar el orden de grabación y así cubrir con los tiempos delimitados establecidos previamente en la etapa de pre producción.

En los planes de rodaje elaborados para esta producción, se tomaron en cuenta básicamente puntos claves como la distancia de locaciones, disponibilidad de tiempo de los especialistas y permisos concedidos por las diferentes empresas. Puesto que los tiempos a cumplir por parte de la productora Figura y Salud SA eran ajustados, se tuvieron que realizar varias entrevistas a los mismos especialistas en una misma locación, permitiendo así avanzar de manera más rápida y poder cumplir con los temas requeridos dentro del tiempo establecido por los productores ejecutivos.

Al momento de realizar el plan de rodaje para los diferentes programas, se tuvo en cuenta un punto muy importante, que era el hecho de que en esta oportunidad solamente una persona iba a ser la encargada de realizar todas las funciones técnicas para el desarrollo de los programas. Es por eso que al momento de la realizar el scouting se hizo una toma de tiempo aproximado para cada una de las áreas de producción audiovisual a realizar, tales como cámara, fotografía, sonido, etc. El desarrollo de este plan de rodaje fue de vital importancia para lograr coordinar tiempos de grabación y edición para la posterior entrega del material a la productora Figura y Salud SA.

\subsubsection{Dirección de arte}

La dirección de arte se contrastó mucho entre la presentadora y los especialistas, ya que según los requerimientos de la casa matriz, para las tomas que se grababan con la presentadora, por lo general se tenían que utilizar espacios abiertos y naturalmente hermosos. Es decir, dentro de la búsqueda de las locaciones se priorizaron lugares con naturaleza tales como hoteles, resort, parques, spa, etc., los que a su vez debían contar con una arquitectura moderna y fresca. 
En cambio, al momento de seleccionar las locaciones para las grabaciones de los entrevistados, la producción nos pidió que en lo posible tratemos de respetar el espacio propio de los mismos. Es por ello que, según el tema a tratar, en las grabaciones a los especialistas podemos encontrar:

- Escenarios muy coloridos y llamativos, especialmente cuando se tocan temas de moda y belleza.

- Espacios más sobrios y fríos cuando se tratan temas médicos, que por lo general suelen ser muy parecidos entre sí, ya que predomina mucho el color blanco tanto en paredes como en la vestimenta de trabajo.
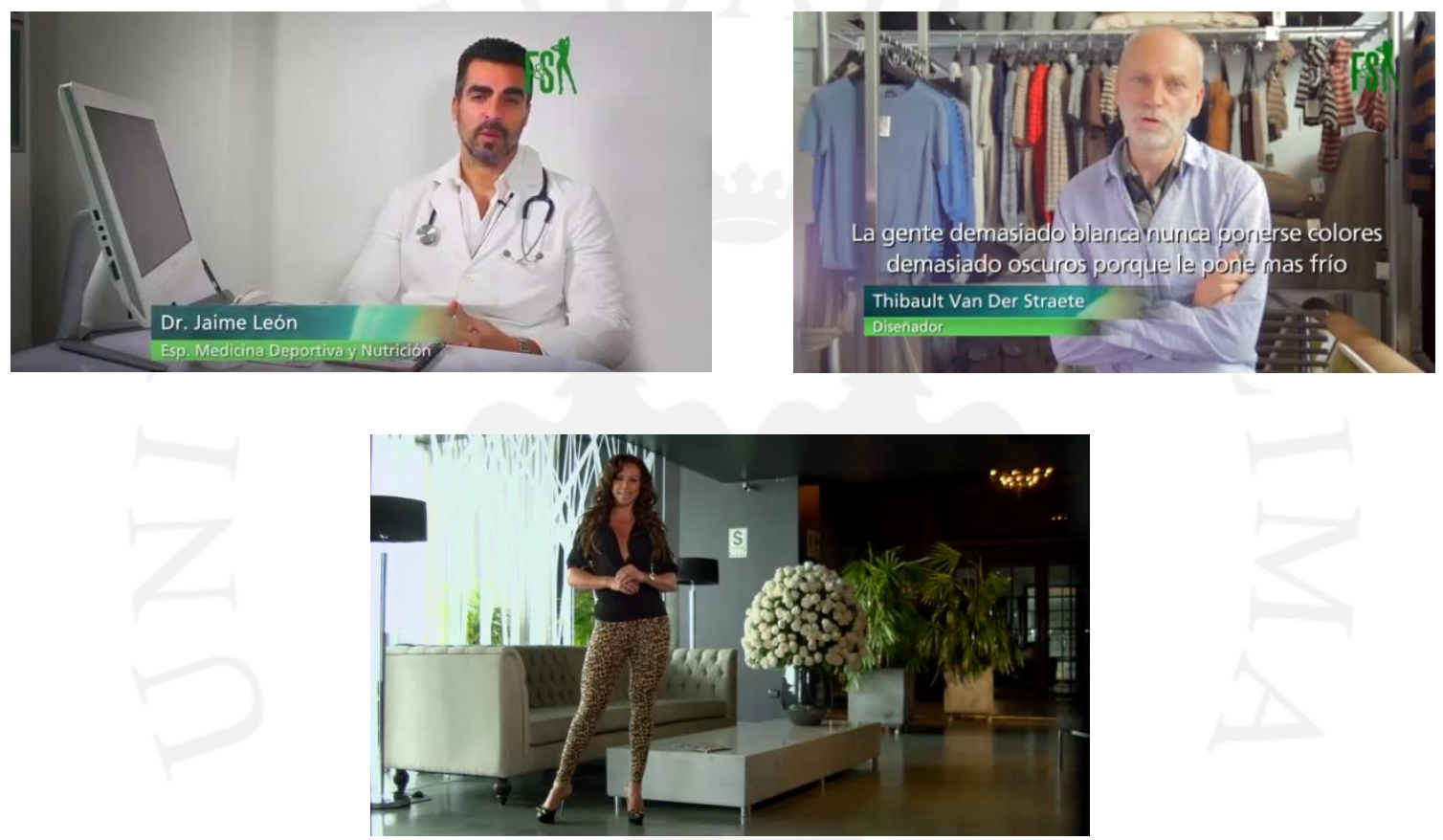

\subsubsection{Tratamiento Fotográfico}

Dentro de los esquemas establecidos por la productora matriz en Venezuela, se solicitó que el tratamiento fotográfico realizado a los especialistas sea de manera sobria y plana, con el fin de brindarle al espectador una sensación de seriedad y profesionalismo. Para esto se manejó un esquema básico de luces (key light, fill light y back light), siempre tratando de mantener o reproducir el ambiente natural de cada locación. 

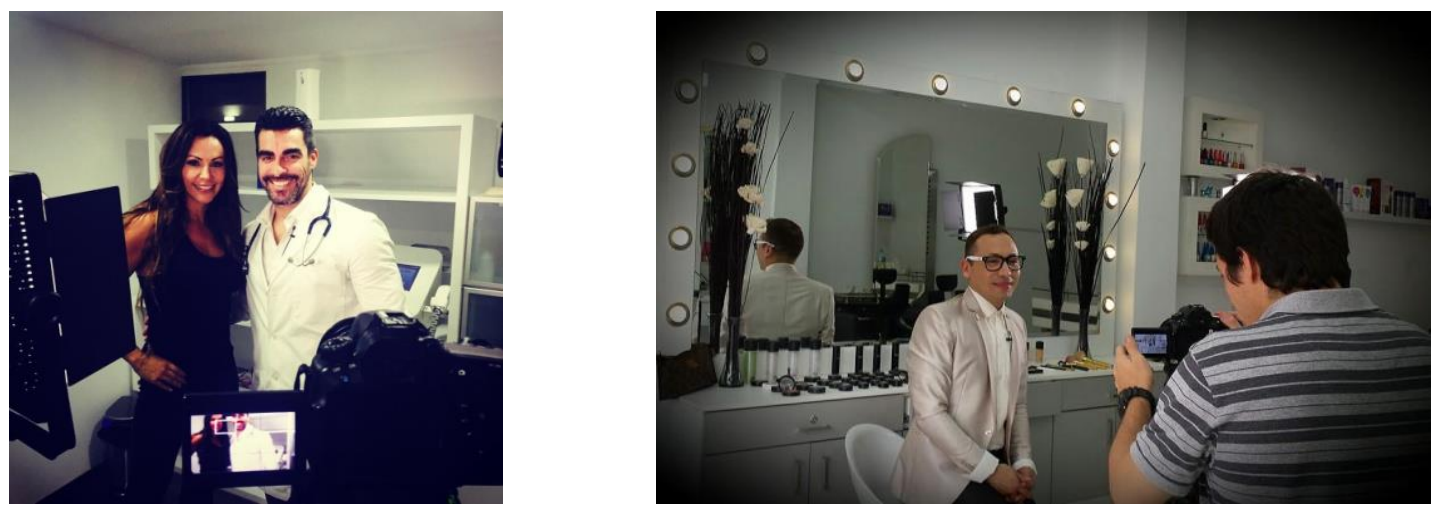

Los planos propuestos por la productora para los especialistas suelen ser estáticos y frontales a la cámara. Esto con el fin de generar la sensación al público de que están siendo atendidos por los invitados. Parte de los cambios propuestos por la productora fue el hecho de reforzar lo dicho por el especialistas mediante tomas de apoyo que mostraran la pericia, profesionalidad y método empleado por los invitados a los pacientes. Cabe recalcar que, como se dijo anteriormente, antes de que la producción se vuelva multinacional, por lo general, los refuerzos visuales se realizaban mediante fotos grabadas con movimientos realizados en postproducción. Parte de la reforma brindada por Simon Mono Producciones fue el obligar o exigir al especialista realizar una muestra in situ del tratamiento del cual estuviera hablando. Dentro de la propuesta para este tipo de refuerzos se usaron cámaras en movimiento, planos detalles, cámara en mano y demás que ayudaron a brindarle más agilidad al programa.

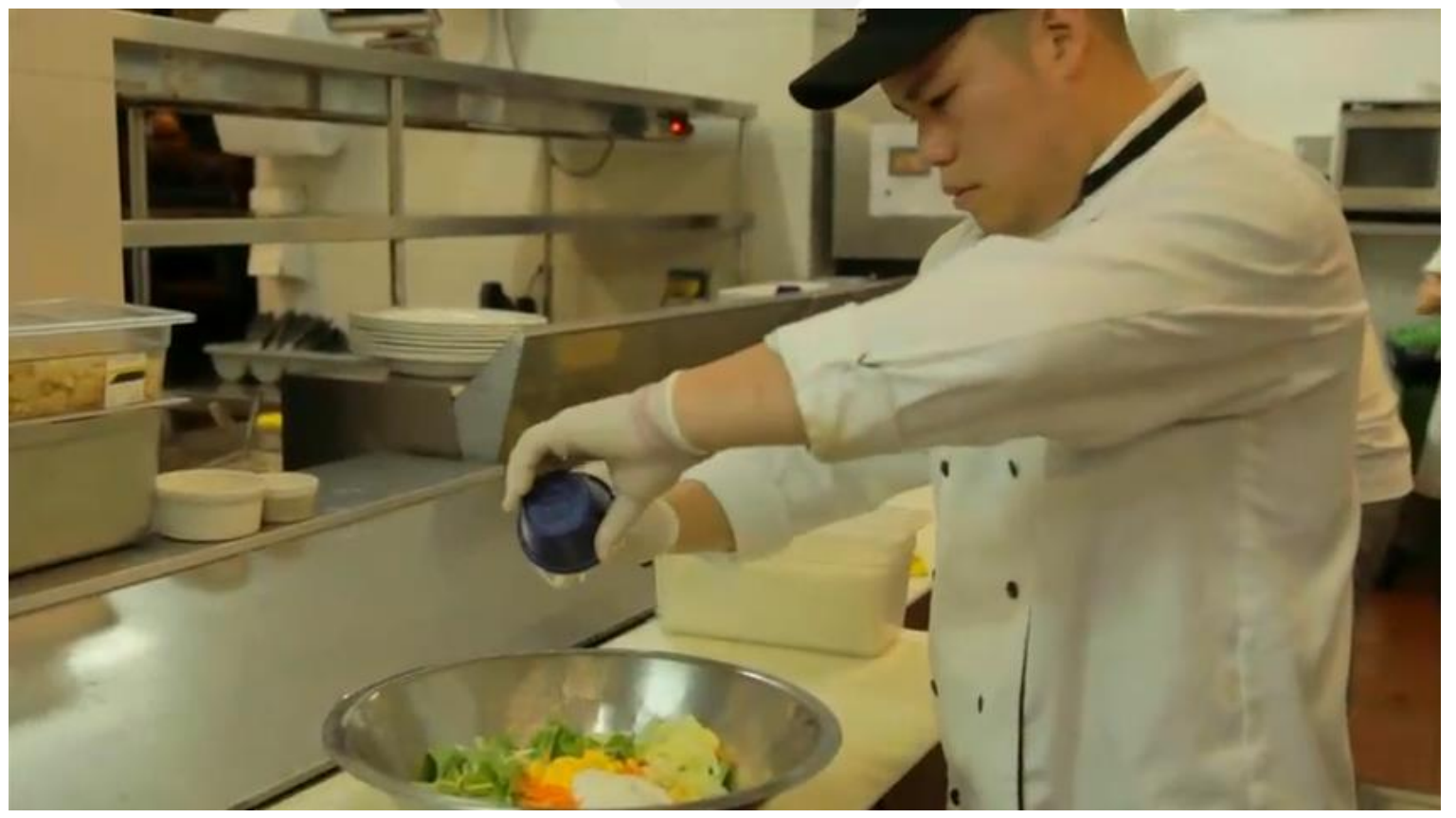




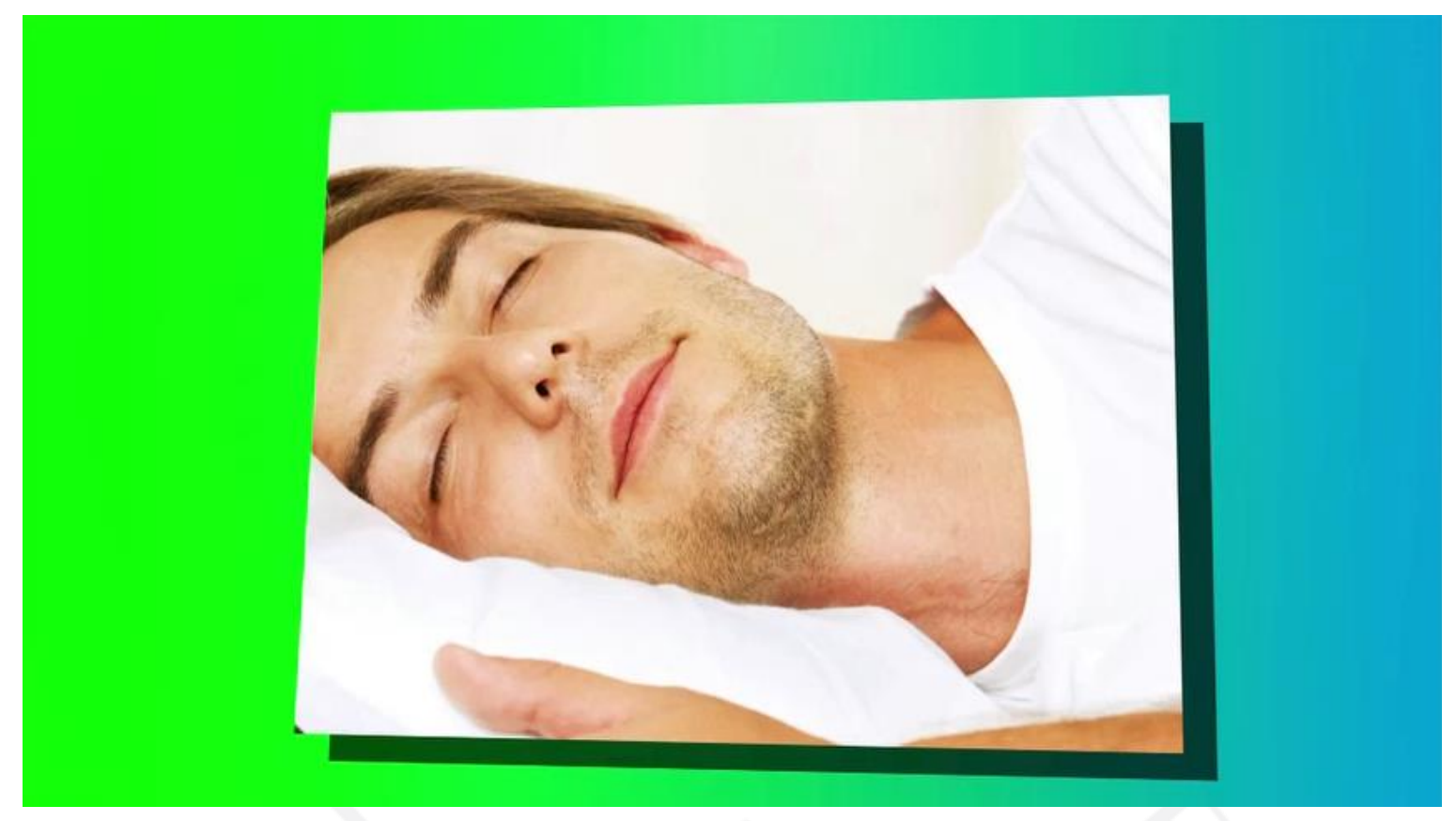

Para la presentadora el tratamiento fotográfico es un poco diferente al de los especialistas, ya que ella suele manejar espacios abiertos, con planos intercalados entre medios y enteros, mayores movimientos de cámara mediante sliders, dolly o mini jibs y luz natural, algunas veces rebotada. Por lo general la presentadora suele trabajar con tonalidades más cálidas, a diferencia de los especialistas, donde se suelen ser utilizar tonalidades más frías.

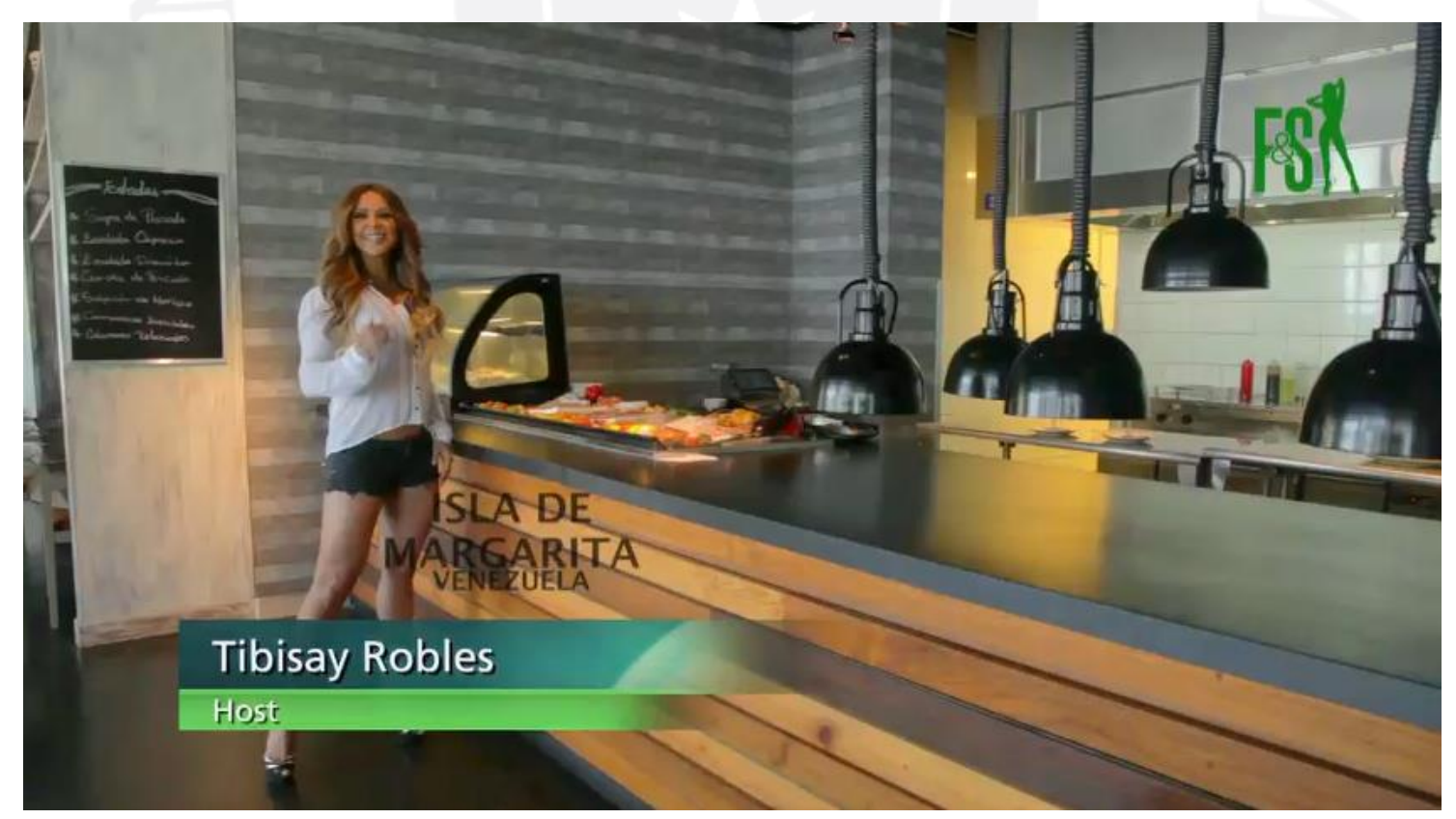




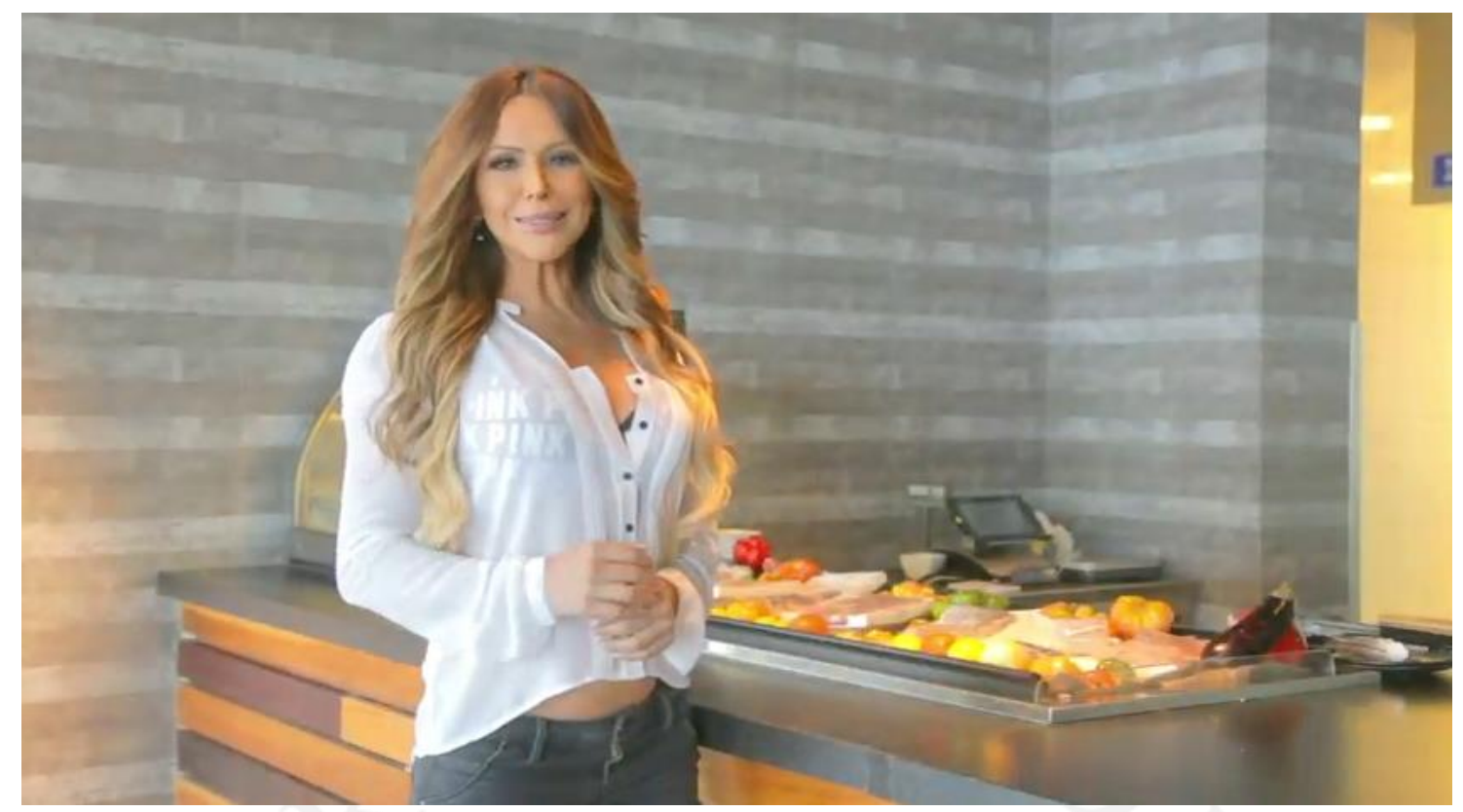

Actualmente se trata de mantener cierta movilidad de cámara, especialmente para los espacios abiertos. Pero muchas veces, cuando se trata de gimnasios, se usa una cámara más estática, aunque igual se mantienen los planos enteros y medios.

Otro estándar que maneja la productora es el de siempre iniciar con tomas de apoyo del lugar donde se encuentra. Por lo general son planos generales, con paneos y tilts, donde se muestran paisajes, artículos, etc.

\subsubsection{Sonido}

El tratamiento del sonido es de mucha importancia, pues representa el 50\% de un trabajo audiovisual. En las diferentes casas realizadoras que aportan a que el programa se desarrolle con la calidad esperada, se le brinda la atención necesaria para que éste salga como la mayor y necesaria calidad y nitidez.

Por lo general, en la etapa de rodaje, se usa sonido directo mediante micrófonos de pecho (lavalier), reforzados con un boom, que van conectados a un grabador de audio independiente, puesto que las cámaras DSLR que se usan para la realización de los programas solo registran un audio referencial. Por la premura con la que se tienen que entregar las grabaciones, no se suele realizar doblaje, ya que muchas veces concretar una cita con los especialistas es complicado. Es por eso que, al visitar previamente las locaciones, es importante tomar en cuenta factores relevantes tales como construcciones, avenidas principales, parques, etc., para evitar la filtración de sonidos ajenos a la producción que puedan causar demoras en la entrega 
programada. Por otro lado, durante la grabación de las imágenes de apoyo no se suele incluir sonido, ya que estas suelen ir acompañadas de la canción representativa del programa, por lo que toda la atención en este punto se centra en el especialista.

Otro factor importante que se toma en cuenta es la dicción de los profesionales. Dentro de la búsqueda que se hace de los especialistas, se determinan cualidades como desenvolvimiento en cámara, facilidad de palabra y una correcta pronunciación. Por lo general, la casa matriz pide que la forma y el tono en que hablen los especialistas de alguna manera exprese calidez, confianza y cercanía, reforzando así la conexión entre el profesional y el público.

\subsection{Postproducción}

Una vez terminadas las etapas de preproducción y producción, se maneja la postproducción.

Como se mencionó anteriormente, hay dos vías que se siguen en la edición según el requerimiento de la productora venezolana. Una es el programa grabado íntegramente en un país y por ende editado en el mismo. Y la segunda es la grabación internacional del programa de manera parcial. Por ejemplo, el segmento de los especialistas podría ser realizado en Perú, por ende editado en dicho país y las tomas de la presentadora en EEUU y editadas allá.

Por lo general, cuando se realiza la segunda opción, la casa matriz en Venezuela suele pedir los proyectos de cada país y ellos se encargan del armado final de todo el programa, realizando muchas veces el corte fino previo a la exportación. En el caso que se realice la primera opción, el íntegro del programa se realiza en el país en cuestión. De todas maneras, siempre se pasa por el filtro de la casa matriz, que brinda la aprobación final para su posterior emisión. Es por eso que los países asociados, cuando realizan la producción del programa, tienen que enviar todo el grueso de las tomas junto con el proyecto editado, para que ellos puedan variar el contenido según lo requieran.

Los programas exigidos por la productora para esta etapa son:

- Adobe Premiere

- Adobe Audition

- After Effects 


\subsubsection{Workflow}

En el caso de que la producción entera del programa esté a cargo de un mismo país, una vez concluidas las etapas de pre producción y producción, éste pasa a cargo del área de postproducción de la casa realizadora, donde primero se realiza el pauteo del material tanto de video como de audio mediante el script realizado en el rodaje. En algunos casos la productora general, Tibisay Robles, realiza un pre visionado de la tomas en bruto, con el fin de revisar algún detalle de información importante que se pudo escapar al momento de realizar el script. Una vez realizado este visionado, el material se ordena en la isla edición mediante folders con nombres fácilmente reconocibles, como:

- Entrevistas.

- Tomas presentadora.

- Tomas de apoyo especialista.

- Tomas de apoyo presentadora.

- Audio presentadora.

- Audio entrevistas.

- Renders.

Luego se inicia con la etapa del montaje, en donde todo será armado según las especificaciones brindadas por la casa matriz en la etapa de preproducción.

En el caso de que sea una producción compartida con otras casas realizadoras afiliadas de diversos países, ésta solo se encargará de pautear, revisar, ordenar y armar un montaje previo solo del segmento asignado. En estos casos, por lo general, la que suele recopilar todo el material es la casa matriz en Venezuela, quien finalmente realiza el montaje del material para su exposición en el programa Vitrina, los días martes en horario matutino.

Cabe resaltar que, independientemente de dónde se realice el montaje del programa, ya sea parcial o total, siempre pasa por una revisión final en la casa matriz en Venezuela, en la cual se podrían dar ajustes de última hora, por lo que siempre se envía el material entero junto con el proyecto y tomas realizadas. Se incluyen renders en calidad media para lograr ser enviados y que puedan ser revisados por los productores venezolanos. 


\subsubsection{Edición}

En lo que respecta a la edición, al ser un micro programa que está incorporado en un programa televisivo de mayor envergadura, esta edición se maneja con un estilo parecido a un Video Clip. Es decir, pequeñas piezas audiovisuales con tomas cortas y rápidas, las cuales tratan de tocar los temas en periodos cortos de tiempo (de dos minutos y medio a tres minutos).

En la mayoría de los casos, las productoras de los diferentes países donde se graba Figura y Salud, no realizan un corte final del programa, sino que según el workflow de trabajo dictado por la productora, solo se encargan de realizar el ordenamiento, pauteo, sincronización de audio con video y corte grueso del material grabado en el país. En otros casos, por órdenes directas de la productora general, Tibisay Robles, el corte fino se puede realizar en un país diferente al venezolano, pero siempre bajo su supervisión. Ella procura que en la edición se incluyan tanto tomas de exterior como de interior, y que en su mayoría predominen tomas de naturaleza y paisajes, principalmente para la presentación del tema.

Siguiendo la línea de la dirección de fotografía, en la colorización se respeta mucho el espacio original del especialista, es decir, no se juega con una paleta de colores determinada, más allá de manipular el contraste y nivelar los blancos.

\subsubsection{Animación}

El recurso de animación para este micro programa está limitado al animar las fotos que cumplen las funciones de tomas de apoyo, que refuerzan lo explicado por el especialista, y a la colocación de las etiquetas donde se exponen los nombres de quien aparece en pantalla, como el de la conductora, el médico o especialista, el tema a tratar en el programa y redes sociales donde se puede encontrar tanto el contenido como la opción de sugerir temas a tocar en futuras emisiones. Este paso por lo general lo realiza la casa productora matriz en Venezuela, ya que ellos cuentan con las plantillas, paleta de colores y un banco de imágenes del cual pueden disponer según sea el tema a tratar.

\subsubsection{Post de sonido / Musicalización}

El área de post de sonido, como tal, recae en la casa productora matriz en Venezuela. Lo que las productoras aliadas en los diferentes países, como es el caso de Simon Mono Producciones, están autorizadas a realizar, es una pre limpieza tanto del audio de las entrevistas como el de la presentadora, mediante el noise reduction de Adobe Audition, además de la eliminación de 
cualquier sonido que se haya filtrado durante la grabación de cada uno de los segmentos. Así también enviamos audios pre nivelados que serán ratificados o modificados por la productora venezolana, según la música y efectos que les vayan a poner.

En lo que respecta a la musicalización, ésta es una creación inédita del Sr. Rafael Pérez talentoso, músico venezolano y amigo cercano de la directora general Tibisay Robles, a quien vendió los derechos de uso desde la primera temporada del programa y se mantiene hasta la actualidad.

\subsubsection{Entrega del material}

Como se ha mencionado en reiteradas ocasiones, una vez que el material se encuentra ordenado, sincronizado, pauteado y trabajado, el proyecto de Adobe Premiere Pro, en conjunto con todas las tomas realizadas, se entrega en un disco duro que provee la misma conductora del programa, o en su defecto se envía mediante internet en plataformas como Wetransfer, al cual, al estar suscrito, permite que se suba a la nube todo el material para que después pueda ser descargado por el editor encargado en Venezuela. Dicho editor luego se encarga de la exportación y posterior colocación para la emisión del programa en el magazine Vitrina. 


\section{Recomendaciones}

Al finalizar el rodaje de esta temporada del programa en mención puedo decir que fue una gran experiencia, me ayudó a seguir creciendo profesionalmente y demostrar que es posible este tipo de producciones unipersonales detrás de cámaras con el debido orden y dedicación para entregar un excelente resultado de talla internacional.

Para concluir este proyecto puedo dar las siguientes recomendaciones, con el fin de que el comunicador audiovisual conozca las consideraciones y los pasos a tomar, previos a la ejecución de un trabajo como éste.

\subsection{Sobre los entrevistados}

Al haber un solo encargado en la producción se debe considerar un máximo de entrevistados, es decir que no exceda de una o dos personas, ya que la coordinación previa con los implicados es parte importante para realizar con éxito el trabajo. Mientras más personas hayan más difícil será concluir con éxito.

\subsection{Sobre la locación}

Otro punto importante a considerar es la locación, ya que ésta debe ser escogida de tal forma que se puedan desarrollar varias tomas y planos, de modo que adicionalmente a la grabación principal puedan realizarse tomas de apoyo. Siendo una producción internacional, se deben mostrar locaciones emblemáticas que muestren la belleza natural de la ciudad a la que se está visitando y desde donde hablan los especialistas. Como es un programa que trata temas de salud, belleza y deporte, es fundamental que el entorno vaya acorde a estos conceptos.

\subsection{Sobre el equipo técnico}

En cuanto al equipo técnico debemos contar con elementos que aseguren un rodaje de calidad, estos deben ser propuestos y designados según el guion técnico que propone el desarrollo de planos y diferentes tomas. Así también considero que estos equipos deben ser prácticos, no debemos llenarnos de accesorios, buscando el equilibrio entre cantidad y calidad, para así lograr con pocos elementos, de fácil movilización y rápida utilización, un excelente resultado final. 


\subsection{Sobre la pre producción}

Considero que esta es la parte más importante para obtener un buen trabajo final. Si contamos con una buena planificación, que todas las entrevistas estén previamente coordinadas, las preguntas analizadas y respondidas y todo el guion debidamente pauteado, optimizaremos el tiempo y los recursos. La dirección, el sonido y la iluminación, son manejadas bajo ciertas condiciones donde haya una buena coordinación, pre producción y permisos. Por otro lado, sugiero que durante el rodaje no se trabaje con mucha gente, esto garantiza que el trabajo de una sola persona en la producción tenga el resultado esperado.

Finalmente puedo acotar que durante el rodaje siempre surgen imprevistos, pero con el orden y coordinación previa todo es manejable y se minimiza el margen de error. Considerando que todo el trabajo de pre producción y producción lo realizó una sola persona, se consiguió un resultado final con éxito, lo que repercutió en la contratación de Simon Mono Producciones para la continuación de otras temporadas. 


\section{Contrato de Exclusividad}

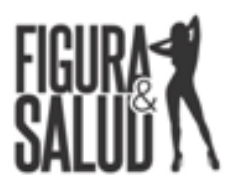

Atención: Universidad de lima

\section{Constancia de ejecución de producción}

Mediante la presente comunicamos que nuestra productora Figura Y salud S.A., con RIF (Registro de Información Fiscal) PJ-042132412 propietaria de los derechos del programa "Figura y Salud con Tibisay Robles" transmitido actualmente en Venezuela por Televen TV en el magazine "Vitrina" todos los martes en horario 9:00am a 11:00am y en streaming en canal youtube.com

Este programa está dirigido a un segmento amplio de la población ofreciendo información en las áreas de salud belleza, nutrición, moda, gastronomía; lo cual nos ha llevado a producir el programa en diferentes países entre ellos Perú.

Siendo "Figura y Salud con Tibisay Robles" un programa de producción multinacional, es clave seguir los lineamientos comunicacionales y estándares de calidad del mismo; por lo cual, en Perú, hemos seleccionado, en estatus de exclusividad, para la dirección, producción y edición del programa a Simon Mono Producciones SAC con RUC 20547791518 y específicamente a su director Jimmy Johnson Ricaurte con C.E.000658807, siendo su función principal, dirigir integralmente toda la producción que sea requerida en el mencionado país.

Se extiende la presente constancia para los fines que sean requeridos.

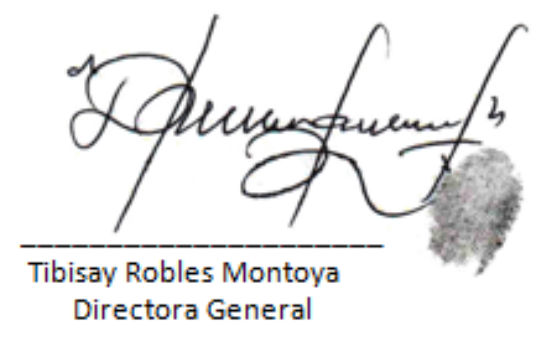




\section{Bibliografía}

Dr. TV (Perú) (sin fecha). En Wikipedia. Recuperado el 17 de noviembre de 2017. https://es.wikipedia.org/wiki/Dr._TV_(Per\%C3\%BA)

Figura y Salud (sin fecha). Propuesta para Latina. Folleto promocional proporcionado por Tisibay Robles (productora general del programa).

Guayoyo Express bate el record de Betty La Fea (29 de marzo de 2013). En Magazine Venezuela, sección farándula. Recuperado el 17 de noviembre de 2017. http://magazine.com.ve/guayoyo-express-bate-el-record-de-betty-la-fea

Landavere Vergara, Luis Alfredo (2016). Lima, Universidad de Lima.

León, Bienvenido (2014). Detrás de las cámaras. Un manual para profesionales de la televisión. Salamanca, Comunicación Social Ediciones y publicaciones.

Robles Montoya Daisy Tibisay - Dtto. Capital - Venezuela ( $\sin$ fecha). Recuperado el 27 de noviembre de 2017. https://www.dateas.com/es/persona_venezuela/robles-montoyadaisy-tibisay-1177222

Televen (sin fecha). En Wikipedia. Recuperado el 27 de noviembre de 2017. https://en.wikipedia.org/wiki/Televen

Vitrina, programa de television (sin fecha). En Facebook. Recuperado el 27 de noviembre de 2017. https://www.facebook.com/TELEVEN.Vitrina/?fref=ts

Vitrina, programa de televisión (sin fecha). En Wikipedia. Recuperado el 27 de noviembre de 2017. https://es.wikipedia.org/wiki/Vitrina_(programa_de televisi\%C3\%B3n) 